\title{
Patient work load and doctor hours in a Norwegian university hospital department
}

\author{
Dag Bratlid* \\ Institute of health and society, Department of health administration and health economics, University of Oslo, Norway
}

Received: March 3, 2019

DOI: $10.5430 /$ jha.v8n3p30
Accepted: April 27, 2019

URL: https://doi.org/10.5430/jha.v8n3p30

\begin{abstract}
Background: Although clinical hospital departments are 24/7 operations, doctor staffing is mainly concentrated during day-time on weekdays, while the rest of the week is covered by on-call systems to secure a minimum of patient care throughout the week. Few studies have investigated how this affects the relation between units of service (UOS) and available doctor hours.

Methods: The study was carried out in a paediatric department with a neonatal intensive care section at a university hospital. Sixty per cent of the admissions were emergency cases. The organization of the 24/7 operation of the department is considered to be representative for most university hospital departments in Norway. UOS were calculated from the average number of in-hospital patients, out-patient consultations, the number of admissions and discharges during three defined time-periods: daytime, evening and night, assuming that all these doctor-patient contacts had the same impact on time use. Gross and net doctor hours on day-time during weekdays, on evenings, nights and weekends were calculated from work schedules, corrected for approved absence and long time sick leave. UOS per hour was calculated as the ratio between UOS and available gross and net doctor hours.

Results: Both available doctor hours as well as UOS per hour varied considerably throughout the week. Eighty-three per cent of doctor hours were concentrated on day-time during weekdays, representing only $24 \%$ of week hours. Evenings and nights representing $76 \%$ of weekly hours, were covered with only $17 \%$ of doctor hours, and all nights through the week and weekend evenings, representing $55 \%$ of weekly hours, were covered with only $7 \%$ of total doctor hours available. Gross and net OUS per hour was increased six-fold and three-fold respectively at day-time on weekends compared to day-time during weekends. Evenings and nights had an even higher UOS per hour.

Conclusion: The distribution of doctor hours through the week does not match UOS per hour. The high work load during weekends, evenings and nights are probably negative for the quality in patient treatment as well as for doctors work conditions. The department is probably understaffed during these time periods. It can also be asked if the department is overstaffed during day-time on weekdays. A more even and balanced staffing of hospital departments in relation to patient work load seems necessary in relation to quality in patient treatment, doctors' working conditions and productivity.
\end{abstract}

Key Words: Doctor hours, UOS per hour, Paediatrics, University hospital, Quality

\section{INTRODUCTION}

Although most of routine patient treatment and elective procedures in hospitals take place on daytime during weekdays, departments with acute admissions still have to be staffed for
24/7 activity. In Norway, however, doctors work plan contracts agreed upon by The Norwegian Medical Association and hospital owners, define doctors as "day-time" workers. All routine treatment and procedures must be scheduled for

*Correspondence: Dag Bratlid; Email: bratlid@ vikenfiber.no; Address: Institute of health and society, Department of health administration and health economics, University of Oslo, Norway. 
and finished by $5 \mathrm{pm}$ on daytime in weekdays only. To take care of acute admissions and acute procedures of in-hospital patients, 24/7 on-call systems are established to secure adequate coverage of necessary hands and competence. To make this on-call system possible, hospital doctors are exempted from the regulations in the national Working Environment Act. As shown in section A2 in Table 1, doctors' weekly work hours are more flexible and allows for longer continuous work periods and less continuous rest between work periods as for most other employees (section A1).

Table 1. Norwegian work schedule regulations according the national Working Environment Act for employees (A1 regulations) and hospital doctors (A2 regulations)

\begin{tabular}{|c|c|}
\hline A1 regulations & A2 regulations \\
\hline $\begin{array}{l}\text { Ordinary work hours } 6 \text { am to } \\
9 \mathrm{pm}\end{array}$ & $\begin{array}{l}\text { Ordinary work hours } 7 \text { am to } \\
5 \text { pm* }\end{array}$ \\
\hline $\begin{array}{l}\text { Maximum } 9 \text { work hours } \\
\text { during } 24 \text { hours }\end{array}$ & $\begin{array}{l}\text { Maximum } 19 \text { work hours } \\
\text { during } 24 \text { hours }\end{array}$ \\
\hline $\begin{array}{l}\text { Total hours less than } 35.5 \text { or } \\
37.5 \text { for } 7 \text { days }\end{array}$ & Less than 60 hours for 7 days \\
\hline $\begin{array}{l}\text { Minimum } 35 \text { hours continuous } \\
\text { off from work during } 7 \text { days }\end{array}$ & $\begin{array}{l}\text { Minimum } 28 \text { hours continuous } \\
\text { off from work during } 7 \text { days }\end{array}$ \\
\hline $\begin{array}{l}\text { Minimum } 11 \text { hours off } \\
\text { between work periods }\end{array}$ & $\begin{array}{l}\text { Minimum } 8 \text { hours off between } \\
\text { work periods }\end{array}$ \\
\hline
\end{tabular}

*At negotiations in 2015 ordinary work hours were revised to be 7 am to $6 \mathrm{pm}$. Doctors not participating in on night call systems could also have ordinary work hours from 7 an to $7 \mathrm{pm}$ once a month. Most hospitals have not implemented these revisions.

Previous Norwegian studies on these issues have looked at the general relation between personnel resources and patient load in hospitals, ${ }^{[1-4]}$ the distribution of doctor's work hours between different activities, ${ }^{[5]}$ as well as on-call staffing in different departments and hospitals. ${ }^{[6]}$ It has been pointed out that Norwegian doctors' work plans results in a disparity between number of hands and competence in relation to patient load, as well as important differences between doctors' work load during day-time on weekdays compared to evenings, nights and weekends. This implies that both the 24/7 quality of patient treatment as well as the quality of doctors' work conditions might be reduced during major parts of a week. No previous study has, however, actually analyzed available doctor hours in relation to variations in patient volume and work load throughout the week. This is the background for the present study.

\section{Materials AND Methods}

The study is based on doctor's staffing and patient load during the months January, February and March 2012 at the Department of paediatrics and adolescent medicine at St. Olavs University Hospital in Trondheim, Norway. The department is both a referral department as well as an emergency de- partment with neonatal intensive care. Sixty per cent of admissions are emergency admissions. The study period was selected because it had 13 full weeks without any national holidays.

\subsection{Gross available doctor hours}

During the study period, the department had 38 full manlabour years, 25 consultants and 13 interns or residents. The analyses on number of doctors working each day were based on every doctors work plan including on-call obligations. Available gross doctor's work hours for each day during the 13-week-study period were calculated and corrected for actual absence according to plan, such as absence prior to and after being on night-call, as well as approved absences for conferences and meetings. Absence due to short term sick leave was not corrected for.

Comparison of gross doctor work hours in relation to patient load were made for three time periods; day-time ( $8 \mathrm{am}-4$ $\mathrm{pm})$, evening ( $4 \mathrm{pm}-8 \mathrm{pm})$, and night ( $8 \mathrm{pm}-8 \mathrm{am})$. These time periods reflect the ordinary day-time schedule for all doctors ( 8 hour work schedule), the ordinary attending staff of four doctors in evenings (one neonatologist, one general paediatrician, and two interns or residents), and one attending resident during night (8 pm - $8 \mathrm{am}$ ). Turn-outs from home by consultants on call during nights were not registered, but the number of such was low.

\subsection{Net available doctor hours}

A doctor's work day is not totally related to direct patient care, but includes also other important activities in a department. A previous study from St. Olavs University Hospital have analysed this at the Department of Obstetrics and Gynaecology and the Department of Internal Medicine. ${ }^{[5]}$ The study found that each doctor on average per workday used 1.2 hours in the out-patient clinic, 1.9 hours for quality and competence improvement, 0.7 hours for teaching, 0.6 hours for administrative work and 0.6 hours for rest and breaks, altogether 3.8 hours. Consequently, for a doctor not working in the out-patient department, the gross work hours of 8 hours ( 8 am to $4 \mathrm{pm}$ ) per day in the clinical wards, were reduced to net work hours of 4.2 , when correcting for the activities mentioned. This is in agreement with a recent study from the Norwegian Medical Association where patient oriented work hours were approximately fifty per cent of gross work hours. ${ }^{[7]}$

The outpatient clinic was organized such that doctors had a full day at the outpatient clinic and therefore did not work with patients in the clinical wards on that day. Since workdays in the out-patient clinic were unevenly distributed between doctors and not specified in the work plans, gross work 
hours in the outpatient clinic could not be calculated from these plans. Instead, an average of 1.2 work hours per day per doctor in the out-patient clinic equals that five doctors of the staff were working in the out-patient clinic every day. ${ }^{[5]}$ The number of doctors available for patient care in the clinical wards was therefore reduced from 38 to 33 doctors in all calculations.

\subsection{Patient care}

Information of patient volume and work load through the different time periods was retrieved from the hospital's Patient Administrative System (PAS). In order to calculate variations in units of service (UOS) per hour such as patient rounds (one doctor contact per each in-hospital patient per time period), examinations and treatment of new patients and discharges (one doctor contact per admitted or discharged patient), the number of in-hospital patients every morning at 8 am as well as exact time for every admission throughout the next 24 hours were registered. While all admissions were registered at real time for admission, it was assumed that all discharges (not registered at real time in PAS) took place between 8 am and $4 \mathrm{pm}$, also on weekends. UOS per hour could then be calculated in relation to available gross doctor work hours on the specific time period studied, day-time, evening and night. On Saturdays and Sundays attending consultant in general paediatrics also did rounds in the maternity ward, on average checking out nine newborns.

In the calculations of total patients work load it was assumed that UOS per hour, such as rounds on in-hospital patients, time for admission of a new patient or discharge of a patient, and time for each out-patient consultation, were equally time consuming. The sum (UOS) of such patient contacts in each period (day, evening and night) was therefore used as a measure of total patient work load in each of these time periods.

The number of out-patient consultations in the out-patient clinic from 8 am to 4 pm on weekdays, were also obtained from PAS. On weekends, evenings and nights when the outpatient clinic was closed, out-patients were also seen in the clinical wards, mainly patients referred for admittance but sent home after examination. These consultations were also registered in PAS at real time for the event.

\subsection{Statistics}

Statistical analyses were carried out with IBM SPSS version 20 and Minitab version 16. Scale variables are given as mean with standard deviation and range. Categorical variables are given as frequencies. Statistical differences between categorical variables were examined by chi-square tests. Statistical significance was defined as $p<.05$.

\section{RESULTS}

Results are presented in Tables 2-5. Since data is not given with decimals, there might be unimportant differences between some tables.

\subsection{Variation in doctor hours and UOS}

Day time (8 am to $4 \mathrm{pm}$ )

As shown in Table 2, the number of attending doctors on weekdays during day-time, including doctors working in the out-patient, clinic varied from 25-34 with a mean of 31 . Total gross work hours varied from 200 to 272 with a mean of 248 . UOS (in-hospital patients, admitted patients, discharges and out-patient consultations) also varied considerably from day to day during this time period.

Table 2. Average number of doctors, gross doctors' hours and units of service (UOS) such as rounds, admissions, discharges and out-patient consultations at day-time, evenings and nights on weekdays and weekends during the study period

\begin{tabular}{lllll}
\hline & \multicolumn{3}{l}{ Monday to Friday } & \multicolumn{2}{l}{ Saturday and Sunday } \\
\cline { 2 - 5 } & Range & Mean & Range & Mean \\
\hline Day- time 8 am-4 pm & & & & \\
Resources & & & & \\
$\quad$ Doctors & $25-34$ & 31 & Fixed & 4 \\
$\quad$ Gross doctor hours & $200-272$ & 248 & Fixed & 32 \\
UOS & & & & \\
$\quad$ In-hospital patients & $31-54$ & 43 & $29-48$ & 39 \\
$\quad$ Admissions & $1-14$ & 7 & $0-6$ & 2 \\
$\quad$ Discharges & $7-25$ & 14 & $3-19$ & 8 \\
$\quad$ Out-patients & $26-88$ & 56 & $0-11$ & 4 \\
Total UOS & $65-181$ & 120 & $32-84$ & 53 \\
Evening 4 pm-8 pm & & & & \\
Resources & & & & \\
Doctors & Fixed & 4 & Fixed & 4 \\
$\quad$ Gross doctor hours & Fixed & 16 & Fixed & 16 \\
UOS & & & & \\
$\quad$ In-hospital patients & $28-42$ & 36 & $26-40$ & 33 \\
Admissions & $0-6$ & 3 & $0-5$ & 2 \\
$\quad$ Out-patients in ward & $0-4$ & 1 & $0-1$ & 1 \\
Total UOS & $28-52$ & 40 & $26-46$ & 36 \\
Night 8 pm-8 am & & & & \\
Resources & & & & \\
Doctors & Fixed & 1 & Fixed & 1 \\
Gross doctor hours & Fixed & 12 & Fixed & 12 \\
UOS & & & & \\
In-hospital patients & $30-50$ & 39 & $27-45$ & 35 \\
Admissions & $0-9$ & 4 & $0-7$ & 4 \\
Out-patients in ward & $0-3$ & 1 & $0-1$ & 1 \\
Total UOS & $30-62$ & 44 & $27-53$ & 40 \\
\hline
\end{tabular}

On day-time on weekends only four doctors were attending, and the out-patient clinic was closed. Some out-patients were in stead seen in the clinical wards. Total UOS in clinical wards in weekends were slightly less (53) compared to weekdays (64). However, day-time on weekends representing almost $10 \%$ of weekly hours had only $4 \%$ of weekly doctor 
hours, while day-time during weekdays, representing only $24 \%$ of weekly hours, had $83 \%$ of doctor hours.

\section{Evenings ( $4 \mathrm{pm}$ to $8 \mathrm{pm}$ ) and nights ( $8 \mathrm{pm}$ to $8 \mathrm{am}$ )}

Attending doctors during evenings and nights with four attending doctors on evenings and one attending doctor during nights, were according to the established on-call system and identical on weekdays and weekends. UOS showed considerable variation also during evenings and nights, and was somewhat higher during nights than during evenings. Evenings and nights, which represents $76 \%$ of the weekly hours, were only covered with $17 \%$ of doctor hours, and all nights through the week and weekend evenings representing $55 \%$ of weekly hours were only covered with $7 \%$ of the total doctor hours available through the week (see Table 2).

\subsection{UOS per available gross doctor hours}

Table 3 shows the relative UOS per hour for doctors working in the clinical wards on weekdays compared to weekends. It seems that during weekends, UOS per available doctor hours was six times higher compared to day-time on weekdays, with a mean value of 1.9 hours in weekends compared to 0.3 hours during weekdays. Furthermore, on evenings and nights, both during weekdays and weekends, UOS per hour was even greater, 2.3-2.5 and 3.3-3.7, respectively. As shown in Table 4, there was also during day-time a considerable variation between the different weekdays in medical staff and UOS, as well as UOS per doctor, with the highest work load on Tuesday and Wednesday.

As pointed out, several important activities In a clinical university department are not related to direct patient care, such as 1.9 hours for quality and competence improvement, 0.7 hours for teaching, 0.6 hours for administrative work and 0.6 hours for rest and breaks, altogether 3.8 hours, reducing the gross work hours of 8 per day to a net of 4.2 work hours, when correcting for these activities. Since these activities are not scheduled for weekends, the effect of these corrections mainly affects work hours on weekdays. On weekends gross day-time work hours are only reduced to 7.4 net hours by correcting for 0.6 hours for rest and breaks, resulting in a somewhat less dramatic difference in net work hours as compared to gross work hours.

The effect of net day-time doctor hours of 4.2 on weekdays and 7.4 on weekends in relation to patient work load is shown in Table 5. Although the difference between weekdays and weekends in available net doctor hours were considerable less than for gross doctor hours, there still was more than a threefold difference in UOS per doctor hours on weekdays than on weekends, 0.6 versus 2.1 , respectively.

Table 3. Average daily UOS and UOS per available doctor hours $24 / 7$ for weekdays compared to weekends for doctors working in clinical wards and in the out-patient clinic

\begin{tabular}{|c|c|c|c|c|c|c|}
\hline & \multicolumn{3}{|c|}{ Monday through Friday } & \multicolumn{3}{|c|}{ Saturday and Sunday } \\
\hline & $\begin{array}{l}\text { UOS mean } \\
\text { and range }\end{array}$ & $\begin{array}{l}\text { Gross doctor' } \\
\text { hours }\end{array}$ & $\begin{array}{l}\text { UOS per doctor } \\
\text { hours }\end{array}$ & $\begin{array}{l}\text { UOS mean } \\
\text { and range }\end{array}$ & $\begin{array}{l}\text { Gross doctor } \\
\text { hours }\end{array}$ & $\begin{array}{l}\text { UOS per doctor } \\
\text { hours }\end{array}$ \\
\hline \multicolumn{7}{|l|}{8 am to 4 pm } \\
\hline In-hospital patients & $43(31-54)$ & & & $48^{*}(29-57)$ & & \\
\hline Admissions & $7(1-14)$ & & & $2(0-6)$ & & \\
\hline Discharges & $14(7-25)$ & & & $8(3-19)$ & & \\
\hline Out-patients in ward & & & & $4(0-11)$ & & \\
\hline Total UOS & $64(39-93)$ & 208 & $0.3(0.2-0.5)$ & $62(32-93)$ & 32 & $1.9(1.0-2.9)$ \\
\hline Out-patient clinic & $56(26-88)$ & 40 & $1.4(0.7-2.2)$ & & & \\
\hline \multicolumn{7}{|l|}{$4 \mathrm{pm}$ to $8 \mathrm{pm}$} \\
\hline In-hospital patients & $36(28-42)$ & & & $33(26-40)$ & & \\
\hline Admissions & $3(0-6)$ & & & $2(0-5)$ & & \\
\hline Out-patients in ward & $1(0-4)$ & & & $1(0-1)$ & & \\
\hline Total UOS & $40(28-52)$ & 16 & 2.5(1.8-3.3) & $36(26-46)$ & 16 & $2.3(1.6-2.9)$ \\
\hline \multicolumn{7}{|l|}{$8 \mathrm{pm}$ to 8 am } \\
\hline In-hospital patients & $39(30-50)$ & & 0.3 & $35(27-45)$ & & \\
\hline Admissions & $4(0-9)$ & & 3 & $4(0-7)$ & & \\
\hline Out-patients in ward & $1(0-3)$ & & & $1(0-1)$ & & \\
\hline Total UOS & $44(30-62)$ & 12 & $3.7(2.5-5.2)$ & $40(27-53)$ & 12 & $3.3(2.3-4.4)$ \\
\hline
\end{tabular}

*included consultations/rounds on 9 newborn infants in the maternity ward.

Note. UOS were calculated as the sum of patient contacts with doctors (one contact per unit per period). Data given as mean values and range 
Table 4. Daytime (8 am to $4 \mathrm{pm}$ ) variations on weekdays in number of staff (doctors) units of service (UOS) such as in-hospital patients (rounds), out-patient consultations, admissions and discharges during the 13-week study period

\begin{tabular}{llllll}
\hline & Monday & Tuesday & Wednesday & Thursday & Friday \\
\hline Doctors & $30 \pm 2$ & $32 \pm 1^{*}$ & $32 \pm 1^{*}$ & $32 \pm 2^{*}$ & $30 \pm 2$ \\
UOS & & & & \\
$\quad$ In-hospital patients & $39 \pm 4^{*}$ & $43 \pm 4$ & $44 \pm 5$ & $45 \pm 3$ & $44 \pm 4$ \\
$\quad$ Out-patient consultations & $50 \pm 12$ & $67 \pm 13^{*}$ & $67 \pm 11^{*}$ & $54 \pm 11$ & $42 \pm 11$ \\
$\quad$ Admissions & $8 \pm 3$ & $9 \pm 1$ & $8 \pm 3$ & $5 \pm 2^{*}$ & $5 \pm 2^{*}$ \\
$\quad$ Discharges & $12 \pm 4$ & $13 \pm 4$ & $15 \pm 5$ & $12 \pm 4$ & $16 \pm 5^{*}$ \\
Total UOS & 109 & $132^{*}$ & $134^{*}$ & 116 & 107 \\
UOS/doctor & 3.6 & $4.1^{*}$ & $4.2^{*}$ & 3.6 & 3.6 \\
\hline
\end{tabular}

$* p<.05$.

Note. Total UOS was calculated as the sum of contacts (one contact per activity) with doctors. Data given as mean and standard deviation.

Table 5. Average available net doctor hours for clinical work in the wards at day-time on weekdays and on weekends

\begin{tabular}{llllll}
\hline \multicolumn{2}{l}{ Monday through Friday } & \multicolumn{3}{c}{ Saturday and Sunday } \\
\hline \multirow{2}{*}{ UOS } & $\begin{array}{l}\text { Doctors } \\
\text { total net } \\
\text { hours }\end{array}$ & $\begin{array}{l}\text { UOS per } \\
\text { doctors } \\
\text { net hours }\end{array}$ & UOS & $\begin{array}{l}\text { Doctors } \\
\text { total net } \\
\text { hours }\end{array}$ & $\begin{array}{l}\text { UOS per } \\
\text { doctors net } \\
\text { hours }\end{array}$ \\
\hline 64 & 109 & 0.6 & 62 & 30 & 2.1 \\
\hline
\end{tabular}

Note. Net doctor hours of 4.2 hours on weekdays were calculated for 26 doctors subtracting 1.9 hours for quality and competence improvement, 0.7 hours for teaching, 0.6 hours for administrative work and 0.6 hours for rest and breaks, altogether 3.8 hours, from the gross work hours of 8 hours, giving a net work hours of 4.2 hours. On weekends gross work hours were only corrected for 0.6 hours for rest and breaks giving 7.4 net hours during daytime. Units of service (UOS) were calculated as the sum of all in-hospital patients, admissions and discharges, assuming that each of these patient contacts should have similar impact on hours used. On weekends also out-patient consultations in the wards and rounds in the maternity ward were included. Data in the Table are based on Tables 2 and 3.

\section{Discussion}

\subsection{Study design}

This study is based on scheduled doctor hours according to work plan and registered UOS related to in-hospital patients, out-patient consultations, admissions and discharges. Since the study was performed at only one clinical department at a university hospital, the results may not be representative for other departments and other Norwegian hospitals. However, the definition of Norwegian doctors as day-time workers from 7 am to $5 / 6 \mathrm{pm}$ on weekdays and the following specific regulations in the national Working Environment Act, applies to all Norwegian hospital doctors (see Table 1). All hospitals are therefore organized with on-call systems similar to the present to cover for necessary patient care during evenings, nights and weekends. The results of the present study should therefore probably be relevant for an evaluation of the organization of work hours and patient care 24/7 in most Norwegian hospitals.

\subsection{UOS as a measure of patient work load}

In the present study it was assumed that a doctor's contact with each of the different patient categories such as in-hospital patients, out-patient consultations, admission of a new patient and discharge of a patient, implied the all UOS represents the same time spent. This may not be correct. However, most out-patient consultations are scheduled to between 30-45 minutes, which also was found in the present study (see Table 3). Admission of a patient also demands a similar time use, when laboratory results and other investigation are included. Although a patient round and discharge of a patient probably on average needs less time, it is time consuming to check on the latest laboratory and radiologic results and give important information and medical prescriptions if needed. The total UOS was therefore regarded as an acceptable alternative to a more detailed study of actual patient handling. However, the study design with comparisons of average UOS in different time periods, will not identify possible differences in patients conditions. A high number of critically ill or complicated intensive care patients in a period with a low UOS could be more challenging than a high UOS in a periods with less challenging patients. However, since this design was applied to all time periods with a relatively high number of patients and probably a similar case mix, any errors in this assumption would have the same impact on all time periods studies. It should, however, be emphasized that the study does not focus on actual time spent with patients, but on relative differences in UOS per available doctor hours. When there are significantly less available doctor hours for similar UOS, it might be concluded that doctors in these periods spend less time with patient than they otherwise would have done, with possible impact for quality and competence in patient treatment.

The study also does not focus on how doctors experience their own workday and schedule. This could have been studied by a questionnaire and prospective observational study on what doctors actually were doing 24/7, but this would not have been possible. A questionnaire will probably also have major flaws by being significantly influenced by condi- 
tions also in private life. It can therefore be concluded that a quantitative study like this probably gives a valid picture of patient work load in the department studied. The results will also highlight time periods where a more observational study could be designed for.

\subsection{Doctor work hours}

In addition to direct patient work, a hospital doctor's workday also contains time for quality and competence improvement, teaching and administrative work which considerable reduces available time for direct patient contact and treatment. Since these activities are usually organized on day-time during weekdays, comparing doctor work hours on weekdays with weekends would not be correct. In the present study comparison between UOS at different time periods were therefore made for both gross doctor work hours (see Table 3) and net doctor work hours, where these activities were corrected for (see Table 5). These corrections were based on the results of a study from 1999 from the same hospital but different departments. It is possible that the impact of such activities has changed since 1999, partly due to the greater use of information technology. ${ }^{[8-10]}$ A recent questionnaire study on work hours of Norwegian hospital doctors concluded, however, that approximately $50 \%$ of a doctor's workday was used for other activities than direct patient work, similar to the corrections made in the present study. Furthermore, a study from Germany from several paediatric departments also found that 3.8 hours were used for direct clinical work in wards, in addition to hours spent in the out-patient clinic. ${ }^{[1]}$

\subsection{Differences UOS and available doctor hours through the week}

The study shows significant differences in doctors day-time work load through the weekdays, with more admissions on Monday through Friday compared to the other days (see Table 4). This is probably caused by more elective patients admitted on these days. This is also reflected in the high number of discharges on Wednesday. The high number of discharges on Friday reflects the effort to reduce the number of in-hospital patients before the weekend. A more even distribution of elective patients and doctor hours throughout the week, would probably result in a more efficient organization of patient care and more efficient use of laboratory facilities and radiology diagnostics.

\subsection{Is the departments understaffed on evenings, nights and weekends?}

The study indicates that UOS per available doctor gross or net hours is much higher on evenings, nights and day-time on weekends compared to day-time on weekdays (see Tables 3 and 5). In addition to less available doctor hours in these time periods, fever doctors attending during these time periods probably also implies that the total competence of staff and therefore the quality of patient treatment is reduced. Even if a higher day-time staffing on weekdays can be explained by many important activities being scheduled for weekdays, there remains a significant difference in day-time UOS also in relation to net doctor work hours, with a work load 34 times higher on weekends than on weekdays (see Table 5). It might therefore be that staffing on weekends, both in available doctor hours and competence, results in reduced quality in patient treatment. Several studies have also shown higher mortality and more often serious complications in patients admitted during weekends and other time periods with reduced staffing. ${ }^{[12-15]}$ Reduced staffing also means less efficiency in patient treatment and longer stay, which also is negative for the patients.

\subsection{Is the departments overstaffed on day-time during weekdays?}

The very large differences in available doctor hours between weekdays and weekends, also indicate that there might be too many doctors attending at day-time on weekdays. As pointed out, the regulation of doctors work plans implies that $83 \%$ of doctor hours are concentrated on day-time during weekdays, representing only $24 \%$ of weekly hours, while all nights through the week and weekend evenings representing $55 \%$ of weekly hours are only covered with $7 \%$ of doctor hours. If the available gross and net doctor hours of one sixth and one third (and lower) on weekends, evening or nights has been regarded as satisfactory by hospital management, the department is probably overstaffed during day-time in relation to UOS. The number of attending doctors in a department is, however, not only related to the need for doctor hours, but also the need for adequate mix of competence within the staff. With an increasingly specialized medicine all doctors do not have the same competence, even in paediatrics. If subspecialized doctors are not also fully included in the work with general patients, but mainly use their time for specialized interests, the department will actually be overstaffed in available gross or net doctor hours in relation to patient load. This is, however, not only a question of how a department is organized, but also a question of how doctors have been able to maintain a general competence within their field. Unfortunately, the development seems to go in the wrong direction. Within the specialty of surgery, with a significant subspecialization, it has in Norway been a growing problem of keeping enough general surgical competence for doctors so they can have on-call responsibility at evenings and nights. ${ }^{[16,17]}$ 


\subsection{Are work plans for Norwegian hospital doctors ap-} propriate?

The very uneven staffing of Norwegian hospitals is a consequence of doctors being considered a day-time worker and exempted from the regulations in the national Working Environment Act in order to establish an on-call system for necessary patient treatment during the rest of the week, as shown in Table 1. As a consequence of this, many hospital resources such as radiology equipment and operating rooms are not being used to their full capacity. In a recent study of operating room efficiency, the Office of the Auditor General of Norway found that $80 \%$ of operations were performed between 8 am and $4 \mathrm{pm}$, and half of the operating rooms were not used after 2:30 pm, because elective operations which would last past 5 pm could not be scheduled. ${ }^{[18]}$ Furthermore, due to the strict regulations of ordinary work hours, hospital administrators have an obligation to secure adequate medical coverage for the rest of the week. This is fulfilled with on-call plans where a limited number of doctors attend on evenings, nights and weekends, as illustrated in the present study. Most doctors do such on-call work once a week or every other week. Particular for these on-call plans is the on-night call, which includes continuous work for at least
16 hours from 4 pm to 8 am or longer (see Table 1). These night calls are unpopular among doctors, who often choose to go on-call with minor illnesses, since it is unpopular to create a vacancy to be filled by your colleagues if you are not very sick. Furthermore, even doctors who report no personal illness, experience these long work periods with a lot of responsibility as exhausting. ${ }^{[19,20]}$ These on-night calls are therefore probably a threat to the safety for both patients and doctors. ${ }^{[21,22]}$

Since a clinical department in a hospital is a $24 / 7$ operation, the work schedule for doctors should probably be organized similar to the work plan for nurses, with a day-time shift, evening shift and night shift, all with reasonable work hours. This would also secure a more efficient use of laboratory services, radiology equipment and operating rooms. Since patient care is becoming more and more a team work between nurses and doctors (and also other personnel), this would probably result in better balanced teams $24 / 7$, with improved quality in patient treatment as a result.

\section{CONFlicts OF INTEREST Disclosure}

The authors declare they have no conflicts of interest.

\section{REFERENCES}

[1] Bratlid D. Har legene en hensiktsmessig fordeling av arbeidstiden? Tidsskr Nor Legeforen. 2012; 132: 1590-1. PMid:22875119. https://doi.org/10.4045/tidsskr.12.0522

[2] Müller TB. En sammenlikning av epler og pærer. Tidsskr Nor Legeforen. 2012; 132: 2038. PMid:23038189. https ://doi .org/10.4 045/tidsskr.12.0987

[3] Bratlid D. Personellressurser og pasientbehandling ved et regionsykehus. Tidsskr Nor Lægeforen. 2000; 120: 3021-6.

[4] Bratlid D. Ventelistesituasjonen ved et regionsykehus. Tidsskr Nor Lægeforen. 2003; 123: 3241-4.

[5] Røhme K, Kjekshus LE. Når tiden telles - sykehuslegers tidsbruk og arbeidsoppgaver. Tidsskr Nor Legeforen. 2001; 121: 1458-61.

[6] Salvesen HB, Trovik J, Børdahl PE. Bemanning og vaktberedskap ved gynekologiske avdelinger og fødeavdelinger i Norge. Tidsskr Nor Lægeforen. 2004; 124: 2780-2.

[7] Rosta J, Aasland OG. Doctors' working hours and time spent on patient care in the period 1994 - 2014. Tidsskr Nor Laegeforen. 2016; 136: 1355. English, Norwegian.

[8] EPJ Monitor. Årsrapport 2010: Oversikt over utbredelse og klinisk bruk av IKT i helsetjenesten. Trondheim: Norsk senter for elektronisk pasientjournal, 2011.

[9] Øvretveit J, Scott T, Rundall TG, et al. Improving quality through effective implementation of information technology in healthcare. Int J Qual Health Care. 2007; 19: 259-66. PMid:17717038. https : //doi.org/10.1093/intqhc/mzm031

[10] Lium JT, Laerum H, Schulz T, et al. From the front line, report from a near paperless hospital: mixed reception among health care profes- sionals. Am Med Inform Assoc. 2006; 13: 668-75. PMid:16929040. https://doi.org/10.1197/jamia.M2108

[11] Mache S, Vitzthun K, Kusma B, et al. Pediatricians' working conditions in German Hospitals: a real time task analysis. Europ J Pediatr 2010; 169: 551-5. PMid:19774393. https://doi.org/10.1007/ s00431-009-1065-2

[12] Bell CM, Redelmeier DA. Mortality among patients admitted to hospitals on weekends as compared with weekdays. N Engl J Med. 2001; 345: 663-8. PMid:11547721. https://doi.org/10.1056/NEJM sa003376

[13] de Graaf JP, Ravelli AC, Visser GH, et al. Increased adverse perinatal outcome of hospital delivery at night. BJOG. 2010; 117: 1098-107. PMid:20497413. https://doi .org/10.1111/j.1471-0528.20 $10.02611 . \mathrm{x}$

[14] Bendavid E, Kaganova Y, Needleman J, et al. Complication rates on weekends and weekdays in US hospitals. Am J Med. 2007; 120: 422-8. PMid:17466653. https://doi.org/10.1016/j. amjmed .2006 .05 .067

[15] Rogers FB, Simons R, Hoyt DB, et al. In-house board-certified surgeons improve outcome for severely injured patients: a comparison of two university centers. J Trauma. 1993; 34: 871-7. https://doi.org/10.1097/00005373-199306000-00019

[16] Johannessen LB. Vaktkompetanse i generell kirurgi. Tidsskr Nor Lægeforen. 2005; 125: 1894.

[17] Bakken C. Vaktkompetanse med kirurgi. Tidsskr Nor Lægeforen. 2007; 127: 3304

[18] Riksrevisjonens unders $\varnothing$ kelse av effektivitet i sykehus. Dokument 3: 4 (2013 - 2014), Oslo 28.11.2013. Available from: https: //riksrevisjonen.no/rapporter/Sider/Sykehus.asp 
[19] Hertzberg TK, Skirbekk H, Tyssen R, et al. The good doctor - strong and persevering. Tidsskr Nor Laegeforen. 2016; 136: 1631-1634. English, Norwegian. PMid:27790889. https ://doi .org/10.404 5/tidsskr.16.0066

[20] Hertzberg TK, Skirbekk H, Tyssen R, et al. The hospital doctor of today - still continuously on duty. Tidsskr Nor Laegeforen. 2016; 136: 1635-1638. English, Norwegian. PMid:27790890. https: //doi.org/10.4045/tidsskr.16.0067
[21] Lockley SW, Cronin JW, Evans EE, et al. Effect of reducing interns' weekly work hours on sleep and attentional failures. N Engl J Med. 2004; 351: 1829-37. PMid:15509816. https://doi.org/10.105 6/NEJMoa041404

[22] Barger LK, Ayas NT, Cade BE, et al. Impact of extended-duration shifts on medical errors, adverse events, and attentional failures. PLoS Med. 2006; 3: e487. PMid:17194188. https://doi .org/10 .1371/journal.pmed.0030487 